\title{
The Epidemiology of Traumatic Spinal Cord Injury in Alberta, Canada
}

\author{
Donna M. Dryden, L. Duncan Saunders, Brian H. Rowe, Laura A. May, \\ Niko Yiannakoulias, Lawrence W. Svenson, Donald P. Schopflocher, \\ Donald C. Voaklander
}

\begin{abstract}
Objectives: To describe the incidence and pattern of traumatic spinal cord injury and cauda equina injury (SCI) in a geographically defined region of Canada. Methods: The study period was April 1, 1997 to March 31, 2000. Data were gathered from three provincial sources: administrative data from the Alberta Ministry of Health and Wellness, records from the Alberta Trauma Registry, and death certificates from the Office of the Medical Examiner. Results: From all three data sources, 450 cases of SCI were identified. Of these, $71(15.8 \%)$ died prior to hospitalization. The annual incidence rate was 52.5/million population (95\% CI: 47.7, 57.4). For those who survived to hospital admission, the incidence rate was 44.3/million/year (95\% CI: 39.8, 48.7). The incidence rates for males were consistently higher than for females for all age groups. Motor vehicle collisions accounted for $56.4 \%$ of injuries, followed by falls $(19.1 \%)$. The highest incidence of motor vehicle-related SCI occurred to those between 15 and 29 years (60/million/year). Fall-related injuries primarily occurred to those older than 60 years (45/million/year). Rural residents were 2.5 times as likely to be injured as urban residents. Conclusion: Prevention strategies for SCI should target males of all ages, adolescents and young adults of both sexes, rural residents, motor vehicle collisions, and fall prevention for those older than 60 years.
\end{abstract}

RÉSUMÉ: L'épidémiologie des lésions traumatiques de la moelle épinière en Alberta, au Canada. Objectifs: Décrire l'incidence et le profil des lésions traumatiques de la moelle épinière et des lésions de la queue de cheval (LMÉ) dans une région géographiquement définie du Canada. Méthodes: L'étude a été effectuée du premier avril 1997 au 31 mars 2000. Les données ont été tirées de trois sources provinciales: des données administratives du Ministry of Health and Wellness de l'Alberta, des dossiers du registre des traumatismes de l'Alberta et des certificats de décès du Bureau du coronaire. Résultats: Quatre cent cinquante cas de LMÉ ont été identifiés. Le taux d'incidence annuel était de 52,5/million de population (IC 95\%: 47,7 à 57,4). Pour ceux qui ont survécu au-delà de l'admission à l'hôpital, le taux d'incidence était de 44,3/million/année (IC 95\%: 39,8 à 48,7). Les taux d'incidence pour les hommes étaient plus élevés que pour les femmes de tous les groupes d'âge. Les accidents de la route étaient responsables de 56,4\% des lésions et les chutes de 19,1\%. L'incidence la plus élevée de lésions due à des accidents de la route se retrouve chez les individus entre 15 et 29 ans (60/million/année) et les blessures reliées aux chutes chez ceux de plus de 60 ans (45/million/année). Les résidents de régions rurales étaient 2,5 fois plus susceptibles de subir une telle blessure que les résidents de régions urbaines. Conclusion: Les stratégies de prévention des LMÉ devraient cibler les hommes de tous âges, les adolescents et les jeunes adultes des deux sexes, les résidents ruraux, la prévention des collisions automobiles et des chutes pour ceux qui ont plus de 60 ans.

Can. J. Neurol. Sci. 2003; 30: 113-121

The impact of traumatic spinal cord injury (SCI) can be catastrophic, especially when accompanied by permanent loss of motor and sensory function. Spinal cord injury is usually associated with high mortality, ${ }^{1,2}$ severe disability and handicap, ${ }^{3-5}$ and prolonged and expensive treatment and rehabilitation. ${ }^{6-9}$ Reported annual incidence rates in North America range from 25 to 93 per million population, ${ }^{10-16}$ with the
From the Department of Public Health Sciences, University of Alberta, Edmonton, AB (DMD, LDS, BHR, LWS, DPS); Division of Emergency Medicine, University of Alberta (BHR); Department of Physical Therapy, University of Alberta, (LAM) Edmonton, AB; Health Surveillance Branch, Alberta Health and Wellness, Edmonton, AB (NY, LWS, DPS); British Columbia Rural and Remote Health Research Institute, University of Northern British Columbia, Prince George, BC (DCV) Canada.

ReCeived August 29, 2002. ACCEPTED IN FINAL FORM November 20, 2002. Reprint requests to: Reprints will not be available from the authors. 
highest incidence occurring among males, and adolescents and young adults. ${ }^{12,13,15,17-19}$ The leading causes of SCI are motor vehicle collisions (MVC), falls, violence, and sports activities. ${ }^{12-}$ ${ }^{15,17-19}$ Since there is currently no cure for SCI, prevention efforts are important. In order to identify risk factors and implement targeted prevention strategies, it is necessary to determine the incidence, cause and circumstances that resulted in injury.

To date there has been limited research on the epidemiology of SCI in Canada. In a survey conducted in 1969 and 1970, Botterell et $\mathrm{al}^{20}$ estimated the incidence of SCI in Ontario as 13 and 16 per million population per year, respectively. A recent population-based study in Ontario used data from the Ontario Trauma Registry to identify SCI-related, acute care hospitalizations during fiscal years 1994-95 through 1998-99. ${ }^{14}$ The annual incidence rates ranged from 37.3 per million (199899) to 46.2 per million (1994-95). The Canadian Paraplegic Association estimates that the current annual SCI incidence rate in Canada is 35 cases per million population. ${ }^{11}$

Tator et $\mathrm{al}^{21,22}$ provided a detailed description of 201 consecutive patients admitted to the Acute Spinal Cord Injury Unit at Sunnybrook Medical Centre in Toronto, Ontario between 1974 and 1981. Most patients were male (79.6\%) and the median age at injury was 27.0 years. Motor vehicle collisions were the greatest cause of injury $(40.8 \%)$, followed by sports and recreational activities $(22.9 \%)$, and work-related incidents $(13.9 \%)$. Injuries at the cervical level were most frequent $(63.2 \%)$. Injuries at the thoracic level occurred in $16.9 \%$ of cases and at the thoracolumbar region in $19.9 \%$. Lesions were classed as complete for $46.2 \%$ of individuals.

$\mathrm{Hu}$ et $\mathrm{al}^{23}$ conducted a population-based study on spinal fractures in Manitoba. The researchers analyzed administrative data from the Manitoba Health Service Insurance Plan for persons who sustained a spinal fracture between April 1, 1981 and March 31, 1984. Of the 122 individuals who suffered a spinal fracture with spinal cord involvement, $34.4 \%$ sustained an injury at the cervical level, $38.5 \%$ at the thoracic level, and $23.8 \%$ at the lumbosacral level. The SCI was unspecified for the remainder $(3.3 \%)$. No information was given on the etiology of SCI.

The Canadian Paraplegic Association conducted a survey in 1995-1996 of a random sample of 966 Canadians with SCI who had been injured for at least five years. ${ }^{24}$ A majority of the survey participants were male $(81 \%)$. More than half were injured between the ages of 15 and 24 years, and $78 \%$ between 15 and 34 years. The participants reported that $47.4 \%$ of injuries were at the cervical level.

In the recent review of data from the Ontario Trauma Registry, there were 2,385 hospital admissions for SCI over the five-year study period. ${ }^{14}$ Males experienced $68.4 \%$ of injuries. Falls and transport-related incidents, including motor vehicle, nonmotorized road vehicle and other transport incidents, were the most common causes of injury $(43.2 \%$ and $42.8 \%$, respectively).

The results of these Canadian studies on the epidemiology of SCI are reasonably consistent with reports from other countries in terms of demographics and etiology. ${ }^{12,13,19,25,26}$ However, studies that are hospital- or institution-based may result in referral bias. ${ }^{22,24,27}$ The Manitoba study that included only patients with a vertebral fracture associated with their SCI includes only a segment of the SCI population. ${ }^{23}$ The Ontario study by Pickett et $\mathrm{al}^{14}$ is the most current and comprehensive study to date. However, as with other Canadian studies, people who died at the scene of injury or who were dead on arrival at hospital have been excluded. ${ }^{14,22,23,27}$ The results of these studies

Table 1. Demographics of spinal cord injury cases in Alberta, Canada, April 1, 1997 - March 31, 2000 (N=450)

\begin{tabular}{|c|c|c|c|c|}
\hline & Year $1 \dagger$ & Year $2 \dagger$ & Year $3 \dagger$ & Total \\
\hline Number of cases $(\%)$ & $159(35.3 \%)$ & $151(33.6 \%)$ & $140(31.1 \%)$ & $450(100 \%)$ \\
\hline Incidence rate / million / year & 57.0 & 52.9 & 47.9 & 52.5 \\
\hline $95 \%$ confidence interval & $48.1,65.8$ & $44.5,61.3$ & $39.9,55.8$ & $47.7,57.4$ \\
\hline Sex (Male $(\%))^{*}$ & $115(72.3 \%)$ & $110(72.8 \%)$ & $97(69.3 \%)$ & $322(71.6 \%)$ \\
\hline \multicolumn{5}{|l|}{ Age } \\
\hline Median & 32.0 yrs. & 34.0 yrs. & 37.5 yrs. & 35.0 yrs. \\
\hline Interquartile range & $20-45$ yrs. & $24-47$ yrs. & $24-51.75$ yrs. & $22-48.25$ yrs. \\
\hline \multicolumn{5}{|l|}{ Level of injury (No. (\%))* } \\
\hline Cervical & $103(64.8 \%)$ & $87(57.6 \%)$ & $87(62.1 \%)$ & $277(61.5 \%)$ \\
\hline Thoracic & $23(14.5 \%)$ & $32(21.2 \%)$ & $23(16.4 \%)$ & $78(17.3 \%)$ \\
\hline Lumbar/Sacral/Cauda Equina & $25(15.7 \%)$ & $24(15.9 \%)$ & $28(20.0 \%)$ & $77(17.1 \%)$ \\
\hline Unspecified & $8(5.0 \%)$ & $8(5.3 \%)$ & $2(1.4 \%)$ & $18(4.0 \%)$ \\
\hline \multicolumn{5}{|l|}{ Etiology (No. $(\%))^{* *}$} \\
\hline Motor vehicle collisions & $95(59.7 \%)$ & $90(59.6 \%)$ & $69(49.3 \%)$ & $254(56.4 \%)$ \\
\hline Falls & $25(15.7 \%)$ & $22(14.6 \%)$ & $39(27.9 \%)$ & $86(19.1 \%)$ \\
\hline Sports \& recreation & $15(9.4 \%)$ & $19(12.6 \%)$ & $17(12.1 \%)$ & $51(11.3 \%)$ \\
\hline Other & $24(15.1 \%)$ & $20(13.2 \%)$ & $15(10.7 \%)$ & $59(13.1 \%)$ \\
\hline
\end{tabular}

$* \mathrm{p} \geq 0.05 ; * \mathrm{p}<0.05$.

†Year 1 = April 1, 1997 - March 31, 1998; Year 2 = April 1, 1998 - March 31, 1999; Year 3 = April 1, 1999 - March 31, 2000. 
will underestimate the magnitude of the problem and may miss important differences in the etiology of SCI. ${ }^{12,13,19}$

The following research presents the results of a populationbased study from the province of Alberta, Canada. The study population includes people who died at the scene of injury as well as those who were hospitalized for SCI. The goal of this research was to fully describe the epidemiology of SCI in a welldefined region for which data are available. Specific questions addressed were: 1) What was the incidence of SCI between April 1, 1997 and March 31, 2000? 2) What was the occurrence of SCI by age, sex, severity of injury and cause? and 3) What risk factors contributed to the occurrence of SCI?

\section{Methods}

\section{Study location}

Alberta is located in western Canada and occupies an area of approximately 661,000 square kilometres. In 1998, the population was estimated as 2.8 million, of which $80 \%$ lived in urban areas. Alberta has a universal publicly funded health care system that guarantees access to medically necessary hospital and medical services for all residents of the province. Virtually all $(>99 \%)$ Alberta residents are registered with the system. ${ }^{28}$

\section{Data sources}

Data for this study were gathered from three sources: the Alberta Ministry of Health and Wellness, the Alberta Trauma Registry, and the Office of the Chief Medical Examiner. The inclusion criteria for the study were: 1) spinal cord injuries or cauda equina injuries of traumatic origin, sustained between April 1, 1997 and March 31, 2000, and 2) Alberta residency at the time of injury.

Spinal cord injury was defined as the occurrence of an acute traumatic lesion of neural elements in the spinal canal (spinal cord and cauda equina) resulting in resolving or permanent neurological deficit. For the purposes of this paper, 'SCI' refers to spinal cord injuries and cauda equina injuries. Cases from the Alberta Health and Wellness databases and the Alberta Trauma Registry were identified by the following International Classification of Diseases, Ninth Revision, Clinical Modification (ICD-9-CM) ${ }^{29}$ diagnostic codes: 806.x (fracture of the vertebral column with SCI) or 952.x (SCI without evidence of spinal bone injury). The use of these two ICD-9-CM codes was based on the "Uniform Data Systems Cases Definition" recommended by the U.S. Centers for Disease Control and Prevention. ${ }^{30}$ This definition has been used extensively in trauma registries and surveillance systems to identify SCI. ${ }^{14,15,19,26,31}$ For the Medical Examiner's files, the operational definition was evidence of SCIs or cauda equina injuries in the autopsy report or death certificate (see below).

\section{Alberta Health and Wellness databases}

Alberta Health and Wellness maintains computerized records of all hospital and medical services in Alberta. Every Albertan has a unique personal health number, which is used to link records among different data sources within the Ministry. Demographic information is maintained in the Alberta Health Care Insurance Stakeholder Registry. ${ }^{28}$ Records of hospitalizations are collected in the Canadian Institute for Health
Information Hospital Inpatient database. ${ }^{28}$ Separation abstracts are completed for each admission by trained medical records nosologists and contain admission and discharge dates, up to 16 ICD-9-CM diagnostic codes, and up to 10 ICD-9-CM procedure codes. A search of the Inpatient database identified Albertans who were hospitalized for SCI during the study period. Cases were included if they had an external cause of injury code (E code) consistent with traumatic SCI, and were admitted for at least one day to a trauma centre in Alberta. Patients were excluded if they had a subsequent diagnosis of a "conversion" disorder (ICD-9-CM code 300.11).

In Alberta, there are four regional trauma centres to which all severely injured patients are routinely transferred. It was assumed that all patients with a suspected SCI would be transferred to a trauma centre for confirmation of diagnosis and treatment. To examine the validity of ICD-9-CM diagnostic codes, a medical record review was conducted of a random sample of patients admitted to a large health region in Alberta. Two trauma centres are located within the health region. Searches were conducted of the inpatient and the emergency department (ED) databases for the period of April 1, 1998 to March 31, 1999. The first search identified patients coded with ICD-9-CM codes 806.x or 952.x (SCI codes). The second search identified patients coded with 805.x (fracture of the vertebral column without mention of SCI), 839.0 - 839.59 (dislocation of vertebra), or 953.x (injury to nerve roots and spinal plexus) (nonSCI codes). To avoid double counting patients who came through the ED prior to hospital admission, the search of the ED database was restricted to patients who died in the ED or who were discharged home without being admitted as an inpatient. Of the 860 patients identified by the searches, 100 had SCI codes and 760 had non-SCI codes. For the SCI codes, a random sample of $30(30.0 \%)$ patients was selected. For the non-SCI codes, a random sample of $20(5.1 \%)$ ED patients and $20(5.5 \%)$ inpatients was randomly selected. A total of 70 charts were reviewed to confirm the documentation of a newly diagnosed traumatic SCI or cauda equina injury, as determined by the presence of neurological damage or absence of motor and/or sensory function.

A separate chart review examined the medical records of all short-stay SCI patients (between one and seven days) who were discharged home from a trauma centre between April 1, 1998 to March 31, $1999(n=13)$. This was done to determine whether they represented valid SCI cases.

In addition to the Inpatient database, the Ambulatory Care Classification System database ${ }^{28}$ was searched to identify individuals who were seen in the ED with a diagnosis of SCI, but who died prior to admission as an inpatient. The Ambulatory Care database is maintained by Alberta Health and Wellness and provides information about each patient encounter in all EDs in the province. For each visit, separation abstracts are completed by trained medical records nosologists and contain admission and discharge dates, up to 10 ICD-9-CM diagnostic codes, and up to 10 ICD-9-CM procedure codes.

\section{Alberta Trauma Registry}

The Alberta Trauma Registry collects detailed information on demographics, severity of injury, etiology, and contributing factors for all severely injured patients who were seen at a 
trauma centre in Alberta. Patients are included if they have an Injury Severity Score (ISS) of 12 or greater. ${ }^{32}$ The ISS is an anatomical scoring system that provides an overall score for patients with single or multiple injuries. The ISS score takes values from 1 to 75 with a higher score indicating increased severity. By definition, a patient with a true SCI will have a score of 12 or greater and, therefore, will be included in this registry. The registry was searched using the ICD-9-CM codes 806.x and 952.x to identify individuals who were admitted with SCI during the study period.

\section{Office of the Chief Medical Examiner}

The Medical Examiner investigates all sudden and unexplained deaths in Alberta. For all cases, an external examination is performed and, if warranted, an autopsy is conducted. Records include the identity of the person, date, time and place of death, and the cause and manner of death. Because the Office of the Medical Examiner updated its database in 1999, two databases were searched: pre-March 1999 and post-March 1999. Both databases are unique and the classification system used is different from those of the Alberta Health and Wellness and Alberta Trauma Registry databases described earlier. The search criteria for the pre-March database were accidental deaths, suicides, and undetermined deaths. For the post-March database, a keyword search was conducted of the 'Medical Cause of Death' section of the death certificate. In consultation with the Office of the Medical Examiner, the keywords used in the search were 'cervical', 'spine', 'spinal', or 'neck'. It was determined that keywords such as 'lumbar' or 'thoracic' were unlikely to appear in the cause of death section, but instead would be noted in the autopsy or external examination report. As well, a search was conducted to identify cases where the cause of death was multiple blunt trauma and where an autopsy had been conducted. Spinal cord injury was confirmed if there was an autopsy or external examination report with specific mention of damage to the spinal cord, if the immediate cause of death on the death certificate was a fractured cervical spine, or if paralysis was noted in the emergency medical services, ED or hospital record.

\section{Duplicate cases}

To eliminate duplicate cases among the three data sources, probabilistic matching was performed. Cases were matched on sex, age or date of birth, date of admission or date of injury, and location of injury. All duplicate matches were assessed and removed from the database prior to analysis.

\section{Ethics}

This study was approved by the Health Research Ethics Board (B: Health Research), at the University of Alberta, Edmonton, Canada. To maintain the confidentiality of patients, all personal identifiers were removed prior to the release of data from the Alberta Ministry of Health and Wellness and the Alberta Trauma Registry.

\section{Analyses}

Population denominators from the Alberta Health Care Insurance Stakeholder Registry were used to construct annual age-sex specific rates of injury. The mid-year population census for 1998 was used for aggregated data. Place of residence (rural or urban) was determined using the postal code reported for each individual in the Stakeholder Registry. Rural residents were identified by the presence of a zero in the second position of their postal code. ${ }^{33}$ This approach has been widely used in the analysis of data within this province. Statistical analyses included Student's t test and chi-square testing, where appropriate (alpha level was set at 0.05).

\section{RESUlts}

\section{Case ascertainment}

\section{Validity of inclusion criteria:}

Based on the chart review, 94\% of inpatients with an ICD-9CM code for SCI had a confirmed SCI (positive predictive value $=94.4 \%$ ). All patients with a confirmed SCI were admitted as inpatients to a trauma centre (sensitivity $=100 \%$ ). Ninety-two per cent of short-stay patients demonstrated neurological symptoms or radiological evidence of injury to the spinal cord. These results confirmed the validity of the inclusion criteria.

From all data sources for the three-year study period, a total of 450 individuals were identified as having sustained a SCI.

\section{Alberta Health and Wellness databases:}

From the Inpatient database, 562 cases were identified. Of these, $210(37.4 \%)$ cases did not meet the criteria for inclusion: $127(22.6 \%)$ were coded as medical/surgical complications, 62 (11.0\%) were not admitted to a trauma centre, $11(2.0 \%)$ sustained their injury prior to April 1, 1997, 7 (1.2\%) were nontraumatic injuries, and $3(0.5 \%)$ were eventually diagnosed with a "conversion" disorder. A total of 352 (62.6\%) cases were identified from the Inpatient database. An additional 14 patients were identified through the Ambulatory Care database. Of these, three patients were dead on arrival (DOA) and 11 died in the ED

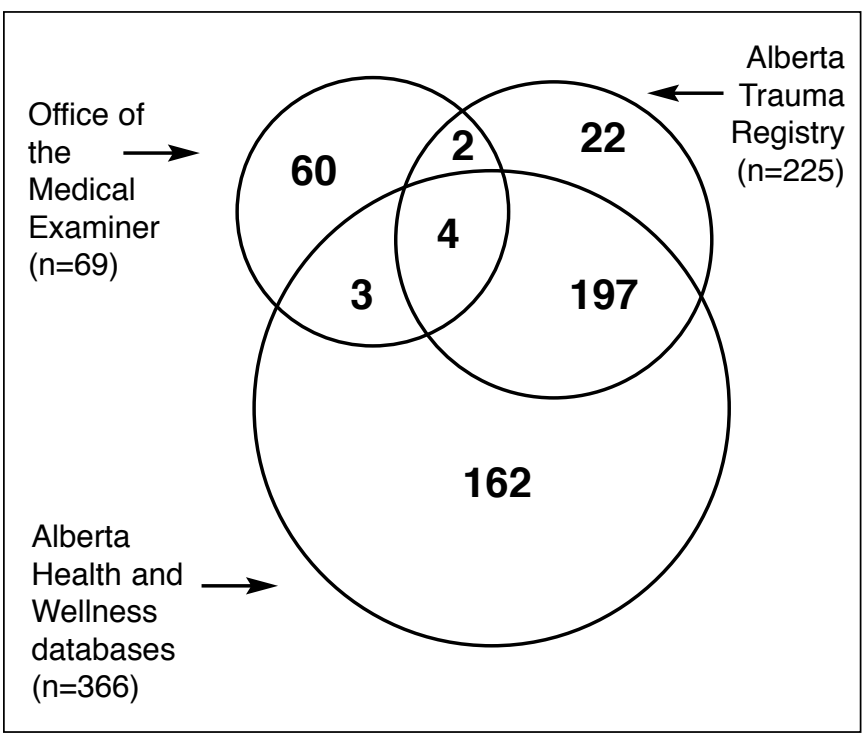

Figure 1: Case ascertainment from three data sources for spinal cord injury in Alberta, Canada, April 1, 1997 - March 31, 2000 (N=450) 




Figure 2: Annual age-sex specific incidence rates for spinal cord injury in Alberta, Canada, April 1, 1997 - March 31, 2000 ( $n=450)$

before they could be admitted. Overall a total of 366 eligible patients were identified from the Alberta Health and Wellness databases (Figure 1).

\section{Alberta Trauma Registry:}

From the Alberta Trauma Registry, a total of 225 cases were identified. Of these, $201(89.3 \%)$ were also located in the Alberta Health and Wellness databases (Figure 1).

\section{Office of the Medical Examiner:}

A total of 1053 records were examined. Of these, 69 files identified a SCI. Fifty-five (79.9\%) deaths occurred at the scene of injury, five (7.9\%) patients were DOA or died in the ED, and nine $(13.0 \%)$ died during hospitalization. Of the 69 cases, 60 $(87.0 \%)$ were located only in the Medical Examiner's files (Figure 1).

Figure 1 shows where the 450 cases were located and the overlap among the three sources. While it was anticipated that all cases identified in the Trauma Registry would appear in the Alberta Health and Wellness databases, in fact, $22(9.8 \%)$ of the trauma registry cases were not located. Because the Medical Examiner collects information on individuals who die at the scene of injury and receive no hospital care, there was little overlap between their records and the other two sources.

\section{Year of injury}

Table 1 shows the demographics of the study cohort. There were no statistically significant differences for sex, age, and level of injury among the three years. For etiology, there was a statistically significant difference between years 1 and 2 and year 3 . In year 3 , there were significantly fewer motor vehicle-related injuries and more fall-related injuries. However, for all years, MVC were the leading cause of injury and falls were the second leading cause. All further analysis in this paper will aggregate data for the three years.

\section{Age and sex}

Of the 450 cases, $322(71.6 \%)$ were male (Table 1). The median age for the total sample was 35.0 years (interquartile range (IQR) 22.0 to 48.25 years). The median age for males was

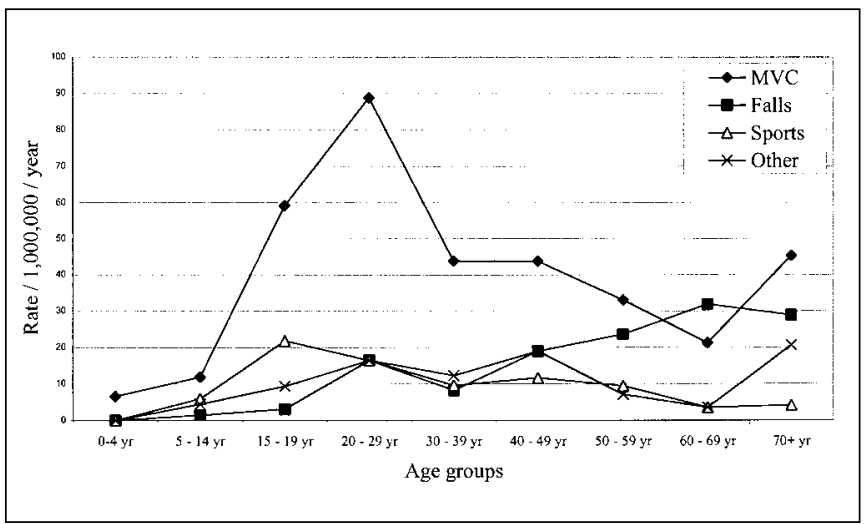

Figure 3: Male age-specific annual incidence rates for etiology of spinal cord injury in Alberta, Canada, April 1, 1997 - March 31, 2000 $(n=322)$

36.0 years (IQR 23.0 to 47.0 years) and for females, the median age was 33.0 years (IQR 20.0 to 54.0 years).

Seventy-one (15.8\%) individuals died before they could be admitted to hospital. Of these, $45(63.4 \%)$ were male. The median age was 27.0 years (IQR 18.0 to 45.0 years). Of the 379 people who survived to hospitalization, 277 (73.1\%) were male. The median age of the hospitalized group was 36.0 years (IQR 24.0 to 49.0 years).

\section{Incidence rates}

The mean incidence rate was $52.5 / 1,000,000$ population per year (95\% confidence interval (CI): 47.7, 57.4) (Table 1). The mean annual incident rate for males was 75.4/1,000,000 population and for females was $29.8 / 1,000,000$. When only those who survived to hospitalization are included, the mean incidence rate was 44.3/1,000,000 population/year (95\% CI: $39.8,48.7$ ). For males, the incidence rate was $64.9 / 1,000,000$ and for females, it was $23.8 / 1,000,000$.

Figure 2 shows the annual age-sex specific incidence rates. For all age groups males had higher incidence than females. The peak incidence rate for males was in the 20 to 29 year age group $(138.0 / 1,000,000)$, with a second peak for those older than 70 years $(98.9 / 1,000,000)$. For females, the peak incidence occurred in the 15 to 19 year age group $(65.3 / 1,000,000)$. The incidence rate for females steadily increased after age 60 peaking at $58.7 / 1,000,000$ for those who were 70 years and older.

The mean incidence rate for urban residents was $32.0 / 1,000,000$ population/year (95\% CI: $27.9,36.2)$. For those living in rural areas, the incidence rate was $72.6 / 1,000,000 /$ year (95\% CI: 60.5, 84.8).

\section{Etiology}

Motor vehicle collisions accounted for the greatest number of SCIs. A total of 254 (56.4\%) individuals were involved in a collision with a motorized vehicle, including drivers, passengers, pedestrians and bicyclists (Table 2). Falls were the second most common cause of injury with $86(19.1 \%)$ people affected. Falls from an elevated level, such as stairs, roofs or ladders, occurred most often $(64 / 86 ; 74.4 \%)$. Falls on the same level (slipping or tripping) were reported in $11(12.8 \%)$ cases. The third most 
Table 2: Etiology of spinal cord injury in Alberta, Canada, April 1, 1997 - March 31, 2000 (N=450)

\section{Cause of injury}

Motor vehicle collisions ( $\mathrm{N}=254 ; 56.4 \%)$

Traffic related

Snowmobile/ATV

Pedestrian

Other motor vehicle collisions

Falls (N=86; 19.1\%)

Building

Stairs

One level to another

Same level (slipping or tripping)

Scaffold/ladder

Unspecified

Sports \& recreation $(\mathrm{N}=51 ; 11.3 \%)$

Diving

Bicycling

Thrown from animal

Skiing/Snowboarding

Other

Unspecified

Struck by object/person ( $\mathrm{N}=24 ; 5.3 \%)$

Intentional ( $\mathrm{N}=20 ; 4.4 \%)$

Assault

Self-inflicted

Other/Unspecified ( $\mathrm{N}=15 ; 3.3 \%)$

Other transportation

Firearms (unintentional)

Overexertion/strenuous movement

Unspecified

Total

Male
$140(43.5 \%)$
$23(7.1 \%)$
$10(3.1 \%)$
$3(0.9 \%)$
$20(6.2 \%)$
$5(1.6 \%)$
$13(4.0 \%)$
$5(1.6 \%)$
$7(2.2 \%)$
$6(1.9 \%)$
$8(2.5 \%)$
$7(2.2 \%)$
$4(1.9 \%)$
$3(0.9 \%)$
$7(2.2 \%)$
$13(4.0 \%)$
$20(6.2 \%)$
$10(3.1 \%)$
$4(1.2 \%)$
$7(2.2 \%)$
$2(0.6 \%)$
$2(0.6 \%)$
$2(0.6 \%)$
322

\section{Male}

$140(43.5 \%)$

$23(7.1 \%)$

$10(3.1 \%)$

$20(6.2 \%)$

$5(1.6 \%)$

$13(4.0 \%)$

$7(2.2 \%)$

$6(1.9 \%)$

$8(2.5 \%)$

$7(2.2 \%)$

$3(0.9 \%)$

$7(2.2 \%)$

$13(4.0 \%)$

$10(3.1 \%)$

$4(1.2 \%)$

\section{Female}

$69(53.9 \%)$

$2(1.6 \%)$

$7(5.5 \%)$

$1(0.8 \%)$

$13(10.2 \%)$

$3(2.3 \%)$

$6(4.7 \%)$

$2(1.6 \%)$

$5(3.9 \%)$

$1(0.8 \%)$

$2(1.6 \%)$

$3(2.3 \%)$

$2(1.6 \%)$

$1(0.8 \%)$

$4(3.1 \%)$

$1(0.8 \%)$

$5(3.9 \%)$

$1(0.8 \%)$

$1(0.8 \%)$

128

\section{Total}

$209(46.4 \%)$

$25(5.6 \%)$

$17(3.8 \%)$

$3(0.7 \%)$

$21(4.7 \%)$

$18(4.0 \%)$

$16(3.6 \%)$

$11(2.4 \%)$

$9(2.0 \%)$

$11(2.4 \%)$

$9(2.0 \%)$

$7(1.6 \%)$

$6(1.3 \%)$

$6(1.3 \%)$

$9(2.0 \%)$

$14(3.1 \%)$

$24(5.3 \%)$

$11(2.4 \%)$

$9(2.0 \%)$

$8(1.8 \%)$

$3(0.7 \%)$

$2(0.4 \%)$

$2(0.4 \%)$

450

Table 3: Distribution of spinal cord injury by level and severity in Alberta, Canada, April 1, 1997 - March 31, 2000 (N=450)

Admitted to hospital (N=379)

\section{Level of lesion}

$\mathrm{C} 1-\mathrm{C} 4$

$\mathrm{C} 5-\mathrm{C} 7$

Cervical unspecified

Thoracic

Lumbar

Sacral, Cauda Equina

Unspecified

\section{Complete}

Incomplete

$\mathrm{C} 1-\mathrm{C} 4$

C5 - C7

Cervical unspecified

Thoracic

Lumbar

Sacral, Cauda Equina

Unspecified
9

26

31

30
73
21
69
6

$\begin{array}{cr}\text { Unspecified } & \text { Total } \\ 38 & 77 \\ 39 & 138 \\ & \\ 23 & 75 \\ & 69 \\ & 6 \\ 14 & 14\end{array}$

8
1
3
2
2

1

$\begin{array}{rr}14 & 23 \\ 2 & 4 \\ 32 & 35 \\ 1 & 3 \\ & 2\end{array}$

4

4

\section{Total}




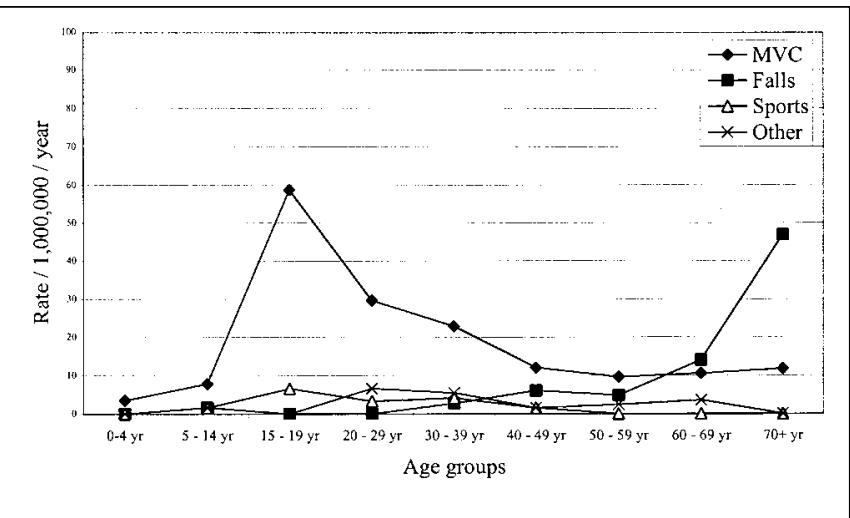

Figure 4: Female age-specific annual incidence rates for etiology of spinal cord injury in Alberta, Canada, April 1, 1997 - March 31, 2000 $(n=128)$

common cause of injury was sports and recreational activities, involving $51(11.3 \%)$ individuals. Diving $(9 / 51 ; 17.6 \%)$, bicycle crashes without motor vehicle involvement $(7 / 51 ; 13.7 \%)$, and being thrown from an animal $(6 / 51 ; 11.8 \%)$ were the leading sports-related causes.

For MVC-related injuries, the highest incidence for males occurred between ages 20 and 29 years, with an annual rate of $88.8 / 1,000,000$ (Figure 3). There was a second, smaller peak for those aged 70 years and older $(45.3 / 1,000,000)$. For females, MVC-related injury was highest in the 15 to 19 age group $(58.8 / 1,000,000)$ (Figure 4$)$. The incidence of motor vehicle injuries for males was higher than for females for all age groups.

For males, the incidence of fall-related injuries steadily increased beginning with the 40 to 49 year age group and leveled off after the age of 60 (Figure 3). For females, fall-related injuries increased sharply after the age of 60 years and surpassed that of males among those older than 70 years (Figure 4). Of the 29 individuals who had a fall on the same level or from stairs, 18 $(62.1 \%)$ were 60 years and older.

\section{Level and severity of injury}

Two hundred and seventy-seven (61.5\%) individuals sustained an injury at the cervical level, while $155(34.4 \%)$ sustained an injury at the thoracic, lumbar or sacral level (Table $3)$. The neurological lesion was complete in $82(18.2 \%)$ cases (Table 3). Persons who died prior to hospitalization were more likely to have been injured at the cervical level than those who were hospitalized $(87.3 \%$ vs. $56.7 \%$; p < 0.001$)$.

The median length of stay in acute care institutions was 15.0 days (IQR 7.0 to 26.0 days). In addition to the 71 people who died before being admitted to hospital, 29 people died during their initial hospitalization. The case fatality rate for all SCIs was $22.2 \%$. For those who survived to hospital admission, it was $7.7 \%$. Of the 100 deaths, $32(32.0 \%)$ individuals died from isolated SCI at the cervical level. Of these, nine were injured at C 1-4, three were injured at C 5-7, and 20 were injured at an unspecified cervical level. Thirty-one $(96.9 \%)$ persons who died from isolated SCI died at the scene of injury or were DOA. Sixty-eight $(68.0 \%)$ persons who died sustained other injuries in addition to their SCI, including head injuries, hemo- or pneumothorax, and multisystem trauma.

\section{DISCUSSION}

This study examined the incidence and pattern of traumatic SCI over a three-year period in a Canadian province with centralized, uniformly coded databases. Case ascertainment was comprehensive and included an examination of all hospital and ED separations in the province, data from a trauma registry, and death certificate reports (chart and autopsy) from a coroner's office. The results of this study suggest that such a strategy is required in order to accurately identify all annual cases of SCI.

Overall, the 450 cases resulted in a mean annual incidence rate of 52.5 per million population. For those who survived to hospital admission, the incidence rate was 44.3 per million, which is higher than the estimate used by the Canadian Paraplegic Association, ${ }^{11}$ but corresponds closely with the rates reported by a recent population-based study from the province of Ontario, Canada. ${ }^{14}$ This close agreement with the Ontario results supports the accuracy of the rates presented in this study. In other population-based studies, the incident rates ranged from 43 to 93 per million population when prehospital deaths are included. ${ }^{12,13,16,25,26}$ When only those who survived to hospitalization are included, the incidence rates ranged from 15 to 83 per million. ${ }^{10,12,13,15,16,26,31,34,35}$

The SCI case fatality rate in Alberta for individuals who were admitted to hospital was $7.7 \%$, which is similar to the rate of $7 \%$ reported by Tator et al. ${ }^{22}$ Population-based studies from the United States have reported case fatality rates ranging from $3.6 \%$ to $21.5 \%$ when restricted to persons who survived to hospital admission. $7,12,13,15,16,26,36$ When persons who died prior to hospitalization are included, the case fatality rate for Alberta was $22.2 \%$ which is within the range of $18.4 \%$ to $78.6 \%$ reported in other studies. ${ }^{12,13,16,26}$

The current study reaffirms that males are at greater risk for SCI than females, with a male to female ratio of

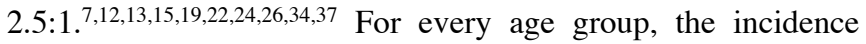
rates for males were higher than for females.

Consistent with other research, the highest incidence occurred among individuals between the ages of 15 and 29 years. ${ }^{7,12,15,26,34}$ A second, smaller peak in incidence occurred in persons over the age of 70 years. A similar increase in injury among older individuals has also been observed. ${ }^{12,13,37}$ Pickett et $\mathrm{al}^{14}$ reported that in Ontario the highest incidence rates were experienced by those 70 years and older. In the current study, the rate for females older than 70 years approached that of the group with the highest incidence (15-19 years), but did not surpass it.

Motor vehicle collisions were the largest cause of SCI for individuals under the age of 60 years. Those older than 60 years were at greater risk for sustaining a fall-related injury. Falls surpassed MVC as the primary cause of injury for females older than 60 years and for males older than 70 years. Similar patterns have been previously reported. ${ }^{12-15,34}$

Overexertion and strenuous movement (E927) was identified as a cause of injury for two individuals in this study (Table 2). From the Alberta Health and Wellness Inpatient database it is not possible to determine the exact circumstances of injury; however, Mikawa et $\mathrm{al}^{38}$ reported on a 52 -year-old man with 
tetraplegia caused by doing push-ups. Other studies have also noted overexertion and strenuous movement as a cause of SCI, however no details as to circumstances were provided. ${ }^{14,34}$

In the present study, the incidence of SCI among rural residents was twice that of urban dwellers. This difference has not been reported in previous research on SCI. However, studies have reported higher rates of injury in general among people who live in rural areas. ${ }^{39-41}$

The data from this study suggest that the strongest efforts at preventing SCI should focus on males, individuals between the ages of 15 and 29 years, rural residents, and MVC. Strategies to prevent SCI in older adults should be directed at the prevention of falls.

This research has also highlighted the importance of using multiple sources of data to obtain a complete picture of SCI. The three data sources enabled more complete case ascertainment. Included were prehospital fatalities, persons with resolving neurological deficits, and those with injuries resulting in permanent neurological impairment. The Alberta Health and Wellness databases identified the greatest number of cases, capturing $81.3 \%$ of the total eligible cases and $93.8 \%$ of hospitalized cases. The Alberta Trauma Registry identified 50\% of the total cases and $57.8 \%$ of hospitalized cases. Use of the Trauma Registry data alone would not only underestimate the incidence of SCI, but also misrepresent the nature and extent of injury. Excluded from the Trauma Registry data are individuals who may have experienced resolving neurological deficits. Research has shown that more than $80 \%$ of patients who were minimally disabled at hospital discharge (functional motor recovery or full recovery) reported some problem or unmet need up to four years following their injury. ${ }^{42}$

In the original search of the Alberta Health and Wellness Inpatient database, 127 individuals sustained a SCI as a result of medical/surgical complications. These patients were excluded from the current study, which was an examination of traumatic SCI. The patients, who underwent a spine-related surgical procedure, were assigned ICD-9-CM codes 998.2 (accidental puncture or laceration during a procedure) and E870.x - E879.x (misadventures to patients during surgical and medical care). No other E code was assigned to the patient visit. It is beyond the scope of the present paper to examine what these cases represent but we note it as a topic that may warrant further investigation.

Potential limitations of this study need to be discussed. First, without access to all medical charts for patients who were identified solely through the Alberta Health and Wellness databases, it is impossible to state unequivocally that SCI was a true diagnosis. While administrative data have been found to have high concordance with chart reviews and patient interviews, ${ }^{23,43,44}$ there is still the possibility of misclassification of cases due to coding errors or incomplete data entry. We did perform chart reviews $(n=83)$ to evaluate our selection criteria for inpatient hospitalizations. Overall, these reviews confirmed the validity of the selection criteria and coding.

Second, the exclusion of patients admitted to a nontrauma centre without a subsequent transfer to a trauma centre (62 cases) may have missed individuals with rapidly resolving neurological deficits and would result in an underestimate of cases. We felt this was necessary, since it is common practice for all true SCIs to be transferred to major trauma centres where neurosurgical assessment and consultation can be obtained. Third, ascertainment of prehospital deaths is likely incomplete. Many patients who died at the scene from multiple severe injuries, especially head trauma, may have had undetected SCIs and would not have been identified through the review of Medical Examiner's files. ${ }^{13,26}$ It is impossible to estimate the number of cases that were undetected and this has not been attempted. Lastly, the data on level and extent of injury reflect discharge diagnoses and do not reflect neurological outcomes or functional recovery that may have occurred following discharge. Notwithstanding the above concerns, this study represents the most comprehensive population-based study on SCI in Canada.

\section{CONCLUSION}

This research has provided a current and accurate measure of the incidence and nature of SCI in a geographically defined region of Canada. Those at highest risk for injury are males, individuals in their late teens or 20s, and rural residents. The most common cause of injury is MVC. For persons older than 60 years, falls become an increasing risk for SCI.

\section{ACKNOWLEDGMENTS}

This research was supported by a grant from the Institute of Health Economics, Edmonton, Alberta, Canada. The Alberta Paraplegic Foundation and the Alberta Heritage Foundation for Medical Research provided support to D.M. Dryden. The Canadian Institute of Health Research (CIHR) supports Dr. Rowe's research through the Canadian Research Chairs (CRC) program. The authors thank the Alberta Trauma Registry, the Alberta Office of the Medical Examiner and the Alberta Centre for Injury Control and Research for their assistance.

\section{REFERENCES}

1. DeVivo MJ, Stover SL, Black KJ. Prognostic factors for 12-year survival after spinal cord injury. Arch Phys Med Rehabil 1992; 73:156-162.

2. Kraus JF, Franti CE, Borhani NO, Riggins RS. Survival with an acute spinal-cord injury. J Chronic Dis 1979; 32:269-283.

3. Trieschmann RB. Spinal cord injuries: psychological, social and vocational rehabilitation. 2nd ed. New York: Demos; 1988.

4. Dijkers MP, Abela MB, Gans BM, Gordon WA. The aftermath of spinal cord injury. In: Stover SL, DeLisa JA, Whiteneck GG, (Eds). Spinal Cord Injury: Clinical Outcomes from the Model Systems. Gaithersburg (MD): Aspen Publishers; 1995:185-212.

5. McColl MA, Walker J, Stirling P, et al. Expectations of life and health among spinal cord injured adults. Spinal Cord 1997; $35: 818-828$

6. Rice DP, MacKenzie EJ, and Associates. Cost of Injury in the United States: a Report to Congress. San Francisco: Institute for Health \& Aging, University of California and Injury Prevention Center, The Johns Hopkins University; 1989.

7. Gerhart KA. Spinal cord injury outcomes in a population-based sample. J Trauma 1991; 31(11):1529-1535.

8. Berkowitz M, O’Leary PK, Kruse DL, Harvey C. Spinal cord injury: an analysis of medical and social costs. New York: Demos Medical Publishing; 1998.

9. DeVivo MJ, Whiteneck GG, Charles ED. The economic impact of spinal cord injury. In: Stover SL, DeLisa JA, Whiteneck GG, (Eds). Spinal Cord Injury: Clinical Outcomes from the Model Systems. Gaithersburg (MD): Aspen Publishers; 1995:234-271.

10. Woodruff BA, Baron RC. A description of nonfatal spinal cord injury using a hospital-based registry. Am J Prev Med 1994; 10(1):10-14.

11. Canadian Paraplegic Association. Spinal cord injury in Canada. 
Available from: URL: http://www.canparaplegic.org/national/ level2.tpl?var $1=$ story $\&$ var $2=20001027122552$. Accessed November 8, 2001.

12. Griffin MR, Optiz JL, Kurland LT, et al. Traumatic spinal cord injury in Olmstead County, Minnesota, 1935-1981. Am J Epidemiol 1985; 121(8):884-895.

13. Kraus JF, Franti CE, Riggins RS, et al. Incidence of traumatic spinal cord lesions. J Chronic Dis 1975; 28(9):471-492.

14. Pickett W, Simpson K, Walker J, Brison RJ. Traumatic spinal cord injury in Ontario, Canada. J Trauma 2002; (in press).

15. Price C, Makintubee S, Herndon W, Istre GR. Epidemiology of traumatic spinal cord injury and acute hospitalization and rehabilitation charges for spinal cord injuries in Oklahoma, 19881990. Am J Epidemiol 1994; 139(1):37-47.

16. Surkin J, Smith M, Penman A, et al. Spinal cord injury incidence in Mississippi: a capture-recapture approach. J Trauma 1998; 45(3):502-504.

17. Burke DA, Linden RD, Zhang YP, et al. Incidence rates and populations at risk for spinal cord injury: a regional study. Spinal Cord 2001; 39:274-278.

18. Nobunaga AI, Go BK, Karunas RB. Recent demographic and injury trends in people served by the model spinal cord injury care systems. Arch Phys Med Rehabil 1999; 80(11):1372-1382.

19. Surkin J, Colley Gilbert BJ, Harkey HL, et al. Spinal cord injury in Mississippi: findings and evaluation, 1992-1994. Spine 2000; 25(6):716-721.

20. Botterell EH, Jousse AT, Kraus AS, et al. A model for the future care of acute spinal cord injuries. Ann R Coll Physicians Surg Can 1975; 8:193-218.

21. Tator CH, Duncan EG, Edmonds VE, et al. Complications and costs of management of acute spinal cord injury. Paraplegia 1993; 31:700-714.

22. Tator $\mathrm{CH}$, Duncan EG, Edmonds VE, et al. Changes in epidemiology of acute spinal cord injury from 1947 to 1981. Surg Neurol 1993; 40(3):207-215.

23. Hu R, Mustard CA, Burns C. Epidemiology of incident spinal fracture in a complete population. Spine 1996; 21(4):492-499.

24. Canadian Paraplegic Association. Workforce participation study of Canadians with spinal cord injuries: demographics, education, employment, income: final report. Ottawa (ON): CPA; 1997.

25. Martins F, Freitas F, Martins L, et al. Spinal cord injuries: epidemiology in Portugal's central region. Spinal Cord 1998; 36(8):574-578.

26. Thurman DJ, Burnett CL, Jeppson L, et al. Surveillance of spinal cord injuries in Utah, USA. Paraplegia 1994; 32(10):665-669.

27. Tator $\mathrm{CH}$, Edmonds VE. Acute spinal cord injury: analysis of epidemiologic factors. Can J Surg 1979; 22(6):575-578.
28. Alberta Health and Wellness. Accessing data for research purposes: a researcher's handbook. Edmonton (AB): Alberta Health and Wellness; 1999.

29. International classification of diseases, 9th revision, clinical modification (ICD-9-CM). Geneva: World Health Organization; 1977.

30. Thurman DJ, Sniezek JE, Johnson D, et al. Guidelines for surveillance of central nervous system injury. Atlanta: Centers for Disease Control and Prevention; 1995.

31. O'Connor P. Incidence and patterns of spinal cord injury in Australia. Accid Anal Prev 2002; 34:405-415.

32. Baker SP, O’Neill B, Haddon W Jr, Long WB. The injury severity score: a method for describing patients with multiple injuries and evaluating emergency care. J Trauma 1974; 14:187-196.

33. Statistics Canada. 1996 census dictionary. Final edition (Cat. No. 92-351-UIE). Ottawa (ON): Statistics Canada; 1999.

34. Acton PA, Farley T, Freni LW, et al. Traumatic spinal cord injury in Arkansas, 1980 to 1989. Arch Phys Med Rehabil 1993; 74(10):1035-1040.

35. Johnson RL, Gabella BA, Gerhart KA, et al. Evaluating sources of traumatic spinal cord injury surveillance data in Colorado. Am J Epidemiol 1997; 146(3):266-272.

36. Burney RE, Maio RF, Maynard F, Karunas R. Incidence, characteristics, and outcome of spinal cord injury at trauma centers in North America. Arch Surg 1993; 128(5):596-599.

37. Warren S, Moore M, Johnson MS. Traumatic head and spinal cord injuries in Alaska (1991-1993). Alaska Med 1995; 37(1):11-19.

38. Mikawa Y, Watanabe R, Fuse K. Quadriplegia caused by push-up exercises. Arch Orthop Trauma Surg 1994; 113:174-175.

39. Baker SP, Whitfield RA, O'Neill B. County mapping of injury mortality. J Trauma 1988; 28(6):741-745.

40. Gabella B, Hoffman RE, Marine WW, Stallones L. Urban and rural traumatic brain injuries in Colorado. Ann Epidemiol 1997; 7(3):207-212.

41. Hwang H-C, Stallones L, Keefe Thomas J. Childhood injury deaths: rural and urban differences, Colorado 1980-8. Inj Prev 1997; 3(1):35-47.

42. Gerhart KA, Johnson RL, Whiteneck GG. Health and psychosocial issues of individuals with incomplete and resolving spinal cord injuries. Paraplegia 1992; 30(4):282-287.

43. Quam L, Ellis L, Venus P, et al. Using claims data for epidemiologic research: the concordance of claims-based criteria with the medical record and patient survey for identifying a hypertensive population. Med Care 1993; 31:498-507.

44. Roos LL, Nicol JP, Cageorge SM. Using administrative data for longitudinal research: comparison with primary data collection. J Chronic Dis 1987; 40:41-49. 